\title{
REGIONAL VARIATIONS OF SOURCE PROPERTIES IN SOUTHERN CALIFORNIA ESTIMATED FROM THE RATIO OF SHORT- TO LONG-PERIOD AMPLITUDES
}

\author{
By Max Wrss and James N. Brune
}

\begin{abstract}
The ratio of short- to long-period amplitude is expressed in terms of apparent stress, rigidity times energy over moment $\left(\mu E_{G} / M_{0}\right)$, for 277 earthquakes in California. A map showing the apparent stresses is compiled. In general, the Mendocino and San Andreas faults as well as the Gulf of California area are regions of large surface-wave excitation and little short-period radiation (low apparent stress). Away from the main fault zones, the apparent stresses tend to be higher. Regions of conspicuously low surface-wave excitation (high apparent stress) are the Laguna Salada-Sierra Juarez region in northern Baja California, the California-Nevada border region north of Bishop, and the region associated with the bend of the San Andreas between San Bernardino and San Gorgonio Mountain. A detailed comparison of earthquakes with accurately-known depths at Parkfield and Borrego Mountain indicates two important differences in apparent stresses between these two source regions. The apparent stress at all depths is larger at Eorrego Mountain than at Parkfield, and it increases with depth at Borrego Mountain, whereas it remains constant at all depths at Parkfield. The explanation for the variation of surface-wave excitation (apparent stress) is not known for certain, but it could be related to variations in true stress.
\end{abstract}

\section{INTRODUCTION}

This study is concerned with regional variations of source spectra of earthquakes. Such variations, if they can be demonstrated to exist, will have important implications for (a) the understanding of tectonic processes, (b) the estimate of earthquake risk, and (c) the detection of underground nuclear explosions. Tectonic processes like earthquakes and fault creep must ultimately be quantitatively understood in terms of rock mechanics. In order to achieve this understanding, it is important to learn how different source materials affect the source parameters which can be estimated from the amplitude spectrum of radiated waves. It is difficult to estimate the earthquake risk on the basis of the seismicity alone. Allen (1968) has taken into account regional peculiarities of the seismicity record before estimating the seismic risk. A map of regional differences in the source parameters together with the seismicity would be the most meaningful tool for earthquake risk evaluation available at present. For the detection of underground nuclear explosions, it is important to know which regions produce earthquakes with spectral contents similar to explosions and which regions do not.

Spectral differences between the seismic signals of shallow earthquakes recorded locally in the western United States can be large. This becomes obvious when the shortperiod and long-period records of equidistant events are compared. In Figures 1, 2, and 3, earthquakes with similar local magnitude, i.e., similar short-period amplitudes, show large differences in the long-period amplitudes. These differences could be due to (a) properties of the paths, (b) the depths of the sources, and (c) source parameters. This study deals with earthquakes in southern California, where the crustal structure 
is not expected to vary so strongly as to locally reduce a selective portion of the seismic spectrum by an order of magnitude. The differences in the path effects are expected to be minor. Good evidence in support of this assumption comes from the observations of the same earthquakes at several stations (Table 2). The measure for long-period radiation $(A R)$ as well as the measure for short-period radiation $\left(M_{L}\right)$ was obtained at several stations for a large number of earthquakes. The results indicate that earthquakes with anomalous ratios of high- to low-frequency content record consistently at the different stations.

Further support for the relative insignificance of the path effects is given by the difference in seismic radiation between the Baja California high-frequency and the Gulf of California low-frequency earthquakes which have almost identical paths to the recording stations. There still could be local low-pass filters in the form of magma chambers surrounding seismic sources which make them appear deficient in high fre-

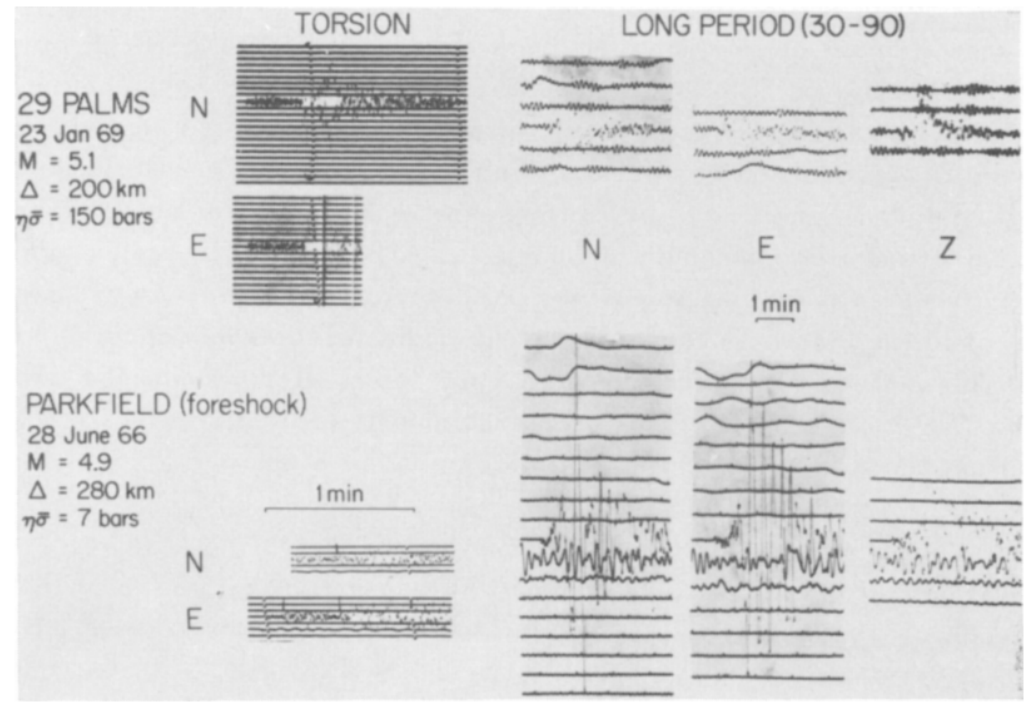

FIG. 1. The short- and long-period records for two earthquakes with similar magnitude and epicentral distance are compared. Records were obtained at Pasadena.

quencies. This, however, can be ruled out at least for those regions through which the high-frequency radiation from Baja California and Nevada has to travel to reach the recording stations. The regions for which the near-source absorption possibility cannot yet be ruled out are the Mendocino and Gulf of California regions. On the whole, however, we feel that it is justified to assume that different absorption properties along different paths play a minor role in modulating the seismic signal.

The source depth strongly affects the Rayleigh-wave excitation at the periods recorded for local earthquakes (e.g., Tsai, 1969). For this reason, earthquakes of equal depth should be compared. Such a comparison is possible for two regions, Parkfield and Borrego Mountain, where the depths of a large number of aftershocks have been determined accurately (Eaton et al., 1970; Hamilton, in preparation). In general, the depths of earthquakes in California do not exceed $16 \mathrm{~km}$, but, within that range, they are not very accurately located. If it is assumed that the average focal depth does not vary throughout southern California, the average spectral ratios of a number of earthquakes in each source region can be compared to each other.

How should the spectral differences be measured? In the ideal study one should 
obtain the complete spectra for a number of phases for each earthquake. Based on these and accounting for crustal structure and source depth, the moment $M_{0}$, fault dimension $r$, dislocation $\bar{u}$, stress drop $\tau$, radiated energy $E_{s}$, and the apparent stress $(c \tilde{\sigma})$ could be estimated. Such a study would mean a major effort. A more feasible approach on the other hand, would be to take the amplitude ratio at two given frequencies. For the present study a modified version of the second approach was chosen.
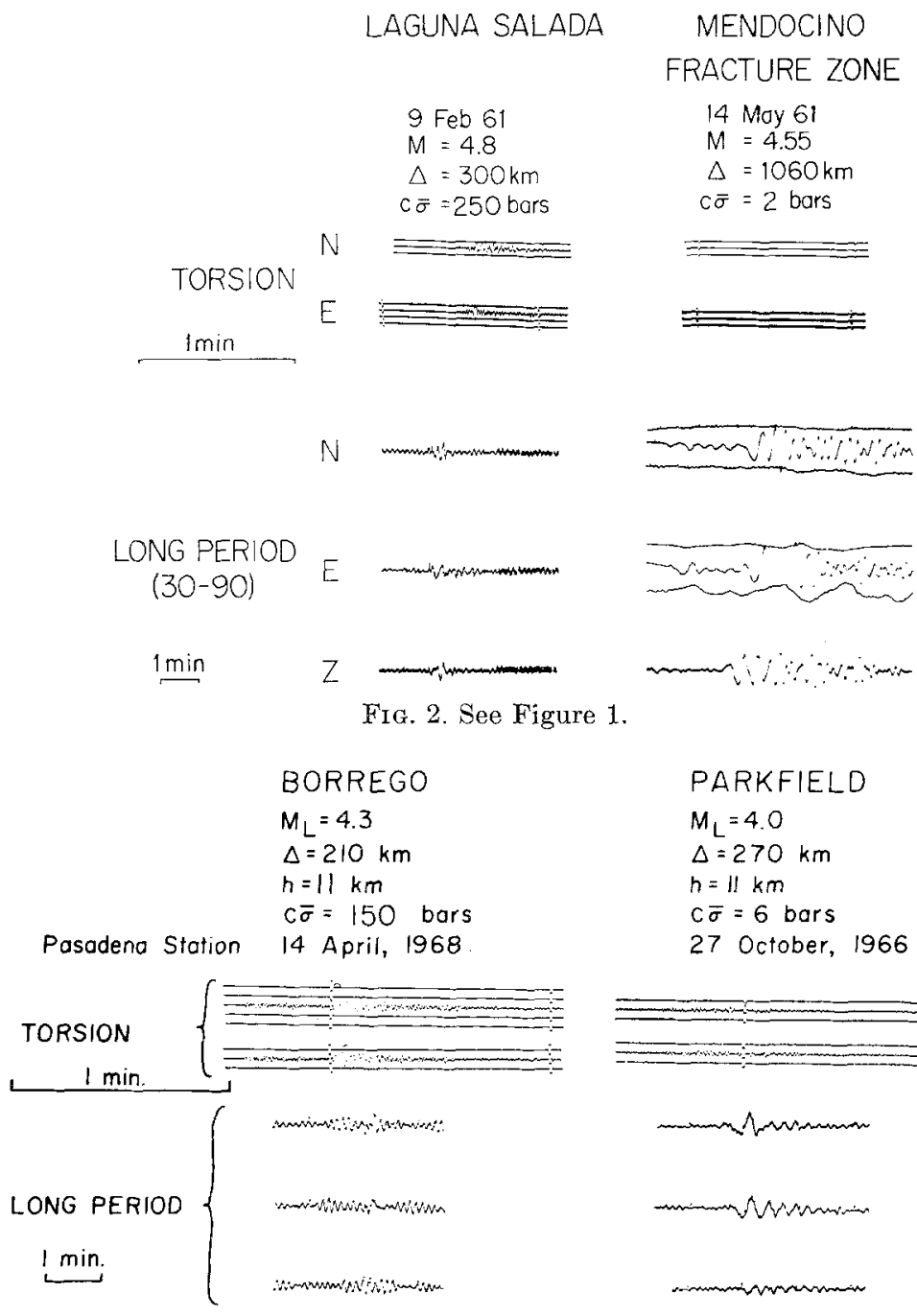

PARKFIELD

$M_{L}=4.0$

$\Delta=270 \mathrm{~km}$

$\mathrm{h}=11 \mathrm{~km}$

$\mathrm{c} \bar{\sigma}=6$ bars

27 October, 1966

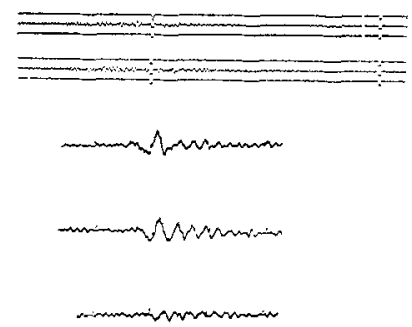

Frg. 3. See Figure 1.

The long-period parameter was $A R$ which was defined by Brune et al. (1963) as the sum of the areas under the surface-wave envelope of the three long-period Press-Ewing components at a given station. The seismic moment was estimated from $A R$ following Wyss and Brune (1968) and disregarding differences in surface-wave excitation due to focal depth and focal mechanism. The local magnitude $M_{L}$ (based on the maximum amplitudes on Wood-Anderson torsion instruments which typically have a period of $0.8 \mathrm{sec})$ was used as a short-period parameter. From $M_{L}$ the Gutenberg Energy $E_{G}$ was estimated. The ratio of $E_{G} / M_{0}$ is finally used as a measure of the relative low-fre- 
quency content of the studied earthquakes. If the two quantities $E_{\theta}$ and $M_{0}$ are indeed good estimates of the seismic energy and the moment, their ratio is equal to a lower bound of the shear strain in the source region (Aki, 1966; Wyss and Brune, 1968). If this ratio is multiplied by the shear modulus $\mu$, the apparent stress is obtained. The advantage of giving the spectral ratios in terms of $\mu E_{\sigma} / M_{0}$ is that the resulting number can be regarded as proportional to the stresses in the source region.

The apparent stress can always be obtained according to the above definitions. However, for earthquakes with different stress drops, the relation of apparent to true average stress may be different since the fractional stress drop affects the long-period part of the spectrum more than the short-period part (Brune, 1969). The earthquakes studied have magnitudes between 3.5 and 5.5. For the smallest or largest earthquakes, the stress drops will be typically a factor of 3 smaller or larger, respectively, than the stress drop for a magnitude 4.5 earthquake (King and Knopoff, 1968; Wyss, 1970). Since we consider order of magnitude differences, we will neglect this effect at the present. In the future, however, one should attempt to determine regional differences in stress drop.

\section{DATA}

The surface-wave envelope areas, $A R$, of 180 earthquakes recorded at Pasadena during the years 1963 to 1968 were determined. The local magnitudes of these earthquakes ranged from 2.7 to 5.8. Epicentral distances ranged from roughly 100 to 1,000 $\mathrm{km}$. $A R$ was normalized to a standard distance of $300 \mathrm{~km}$ using the distance corrections by Brune el al. (1963). From the standardized envelope area $A R_{300}$, the seismic moment was estimated using the relation given by Wyss and Brune (1968). This procedure gives only approximate moments, because the excitation of fundamental mode surface waves varies with depth. The radiation pattern was in general unknown and could not be taken into account. The effect on $A R$ due to different positions on the radiation pattern is believed to be small since $A R$ is defined as the sum of Rayleigh and Love waves on all three components.

The local magnitudes $M_{L}$ determined by the California Institute of Technology (Richter et al., 1967; Allen et al., 1968) were used to estimate the seismic energy $\log E_{G}=1.5 M_{L}+11.8$ (Gutenberg and Richter, 1956). It has recently been pointed out to us (Hanks, personal communication) that this widely-used relationship was originally based on surface-wave magnitude, and another relationship might be more appropriate for local magnitude. However, we have not made such a change, partly for convenience and partly because true relationship is so poorly known and the differences are not critical to the results obtained here. Generally, $M_{L}$ was an average obtained from several southern California stations. In this paper $E_{G}$ is meant to be nothing more than a measure of the high-frequency level of the spectrum with the units of energy.

We proceed now to express the ratio of high to low frequency by

$$
\mu \frac{E_{Q}}{M_{0}}=\mu(c \bar{\epsilon})=(c \bar{\sigma})
$$

where $c$ is the seismic efficiency. It must be remembered that even though the result has the units of pressure, the apparent stress $(c \bar{\sigma})$ is only approximately proportional to the stress in the source region. Particularly for earthquakes deeper than the average California depth, the moment was relatively underestimated and the apparent stress was relatively overestimated. This bias is of no importance if we compare earthquakes with the same depth.

In this procedure, it has been assumed that the shear modulus $\mu$ is constant and 
TABLE 1

AR Values Recorded at Pasadena

\begin{tabular}{|c|c|c|c|c|c|c|c|c|c|c|c|}
\hline \multicolumn{2}{|c|}{ Date } & & \multirow[t]{2}{*}{$M_{L}$} & \multirow[t]{2}{*}{$\begin{array}{l}A R_{300} \\
\left(\mathrm{~mm}^{2}\right)\end{array}$} & \multirow[t]{2}{*}{$\underset{\quad E_{G} / M_{0}}{(\text { bars) }}$} & \multicolumn{2}{|c|}{ Date } & \multirow{2}{*}{$\begin{array}{r}\text { Hour } \\
22\end{array}$} & \multirow{2}{*}{$\begin{array}{l}M_{L} \\
3.7\end{array}$} & \multirow{2}{*}{$\frac{\begin{array}{c}A R_{300} \\
\left(\mathrm{~mm}^{2}\right)\end{array}}{3}$} & \multirow{2}{*}{$\begin{array}{l}\underset{(\mathrm{bars})}{\mu E_{G / M}} \\
\sim 180\end{array}$} \\
\hline 1959 & & & & & & & 10 & & & & \\
\hline \multirow{3}{*}{ Jul } & 29 & 16 & 2.9 & 2 & 17 & & 12 & 17 & 3.1 & 0 & $>22$ \\
\hline & 29 & 20 & 3.1 & 8 & 8 & 1964 & & & & & \\
\hline & 29 & 21 & 3.3 & 22 & 6 & Jan & 6 & 23 & 3.8 & 20 & 38 \\
\hline \multirow[t]{2}{*}{$\operatorname{Aug}$} & 3 & 15 & 3.5 & 47 & 6 & & 6 & 23 & 4.5 & 456 & 19 \\
\hline & 3 & 17 & 2.9 & 2 & 17 & & 30 & 11 & 3.4 & 0 & $>63$ \\
\hline \multicolumn{2}{|c|}{1960} & & & & & & 30 & 11 & 3.5 & 0 & $>90$ \\
\hline \multicolumn{2}{|c|}{ Jan 20} & 03 & 5.3 & 8,460 & 16 & Feb & 3 & 08 & 5.0 & 10,400 & 5 \\
\hline \multirow{2}{*}{\multicolumn{2}{|c|}{ Nov 3}} & 06 & 4.8 & 342 & 70 & & 3 & 09 & 4.5 & 1,080 & 8 \\
\hline & & & & & & & 3 & 13 & 4.5 & 714 & 12 \\
\hline \multirow[t]{2}{*}{ Jan } & 9 & 06 & 4.0 & 29 & 53 & & 7 & 22 & 4.4 & 265 & 23 \\
\hline & 13 & 02 & 4.2 & 645 & 5 & & 7 & 22 & 4.2 & 245 & 12 \\
\hline \multirow[t]{2}{*}{ Mar } & 1 & 00 & 5.0 & 1,700 & 28 & & 21 & 03 & 4.5 & 279 & 31 \\
\hline & 4 & 20 & 4.0 & 57 & 26 & May & 22 & 02 & 3.8 & 6 & 120 \\
\hline Apr & 12 & 05 & 3.9 & 20 & 54 & & 31 & 06 & 3.7 & 0 & $>180$ \\
\hline & 26 & 01 & 4.0 & 0 & $>500$ & Jun & 6 & 11 & 4.3 & 130 & 33 \\
\hline May & 3 & 02 & 4.2 & 17 & 180 & Aug & 1 & 18 & 3.5 & 9 & 30 \\
\hline & 3 & 08 & 3.8 & 1 & 750 & & 4 & 20 & 3.9 & 24 & 45 \\
\hline & 3 & 17 & 3.8 & 0 & $>250$ & Sep & 4 & 20 & 4.0 & 3 & 500 \\
\hline & 3 & 17 & 3.6 & 0 & $>130$ & Oct & 5 & 01 & 4.1 & 43 & 50 \\
\hline & 5 & 13 & 3.0 & 2 & 24 & & 5 & 01 & 4.4 & 88 & 69 \\
\hline & 7 & 19 & 3.3 & 6 & 22 & Nov & 2 & 11 & 4.5 & 84 & 100 \\
\hline & 8 & 00 & 2.7 & 2 & 8 & & 8 & 01 & 4.0 & 14 & 107 \\
\hline & 23 & 06 & 4.3 & 150 & 28 & & 21 & 17 & 4.2 & 160 & 20 \\
\hline & 23 & 06 & 3.3 & 17 & 8 & & 23 & 23 & 4.0 & 0 & $>500$ \\
\hline & 23 & 06 & 3.8 & 32 & 24 & 1965 & & & & & \\
\hline & 23 & 15 & 4.8 & 1,335 & 18 & Jan & 1 & 07 & 3.9 & 98 & 11 \\
\hline & 23 & 17.1 & 3.5 & 26 & 11 & & 1 & 08 & 4.4 & 465 & 13 \\
\hline & 23 & 17.7 & 3.5 & 1 & $>90$ & Feb & 14 & 20 & 3.5 & 0 & $>90$ \\
\hline & 23 & 18 & 3.7 & 117 & 5 & Mar & 28 & 02 & 3.5 & 0 & $>90$ \\
\hline & 28 & 11 & 3.6 & 30 & 13 & Apr & 15 & 20 & 4.5 & 354 & 24 \\
\hline Jun & 11 & 15 & 5.8 & 4,620 & 170 & Jun & 16 & 02 & 4.4 & 428 & 14 \\
\hline & 21 & 23 & 3.7 & 66 & 8 & & 16 & 03 & 3.6 & 4 & 100 \\
\hline Jul & 18 & 19 & 3.9 & 58 & 19 & & 16 & 09 & 3.7 & 12 & 45 \\
\hline & 19 & 15 & 3.6 & 28 & 14 & & 23 & 16 & 3.8 & 0 & $>250$ \\
\hline & 30 & 17 & 3.3 & 0 & $>45$ & Jul & 16 & 07 & 4.0 & 38 & 40 \\
\hline & 30 & 22 & 3.4 & 0 & $>63$ & & 27 & 14 & 4.3 & 372 & 12 \\
\hline Aug & 15 & 21 & 4.2 & 6 & 500 & & 27 & 15 & 3.7 & 97 & 6 \\
\hline & 22 & 04 & 4.4 & 40 & 150 & Aug & 15 & 23 & 4.0 & 82 & 19 \\
\hline & 22 & 12 & 3.5 & 17 & 16 & & 19 & 20 & 3.8 & 14 & 54 \\
\hline & 28 & 12 & 2.8 & 0 & $>8$ & Sep & 6 & 18 & 3.4 & 1 & 190 \\
\hline Sep & 14 & 18 & 2.9 & 0 & $>11$ & & 10 & 14 & 3.5 & 0 & $>90$ \\
\hline & 15 & 10 & 3.2 & 0 & $>32$ & & 16 & 04 & 5.4 & 15,000 & 13 \\
\hline & 22 & 00 & 3.3 & 0 & $>45$ & & 19 & 15 & 4.8 & 950 & 25 \\
\hline & 23 & 14 & 5.0 & 1,675 & 29 & & 22 & 21 & 4.5 & 110 & 78 \\
\hline & 25 & 08 & 3.8 & 22 & 34 & & 25 & 17 & 5.2 & 2,450 & 39 \\
\hline & 25 & 11 & 3.8 & 19 & 40 & & 25 & 17 & 4.9 & 1,090 & 31 \\
\hline Oet & 8 & 23 & 3.7 & 17 & 32 & & 26 & 07 & 5.0 & 800 & 60 \\
\hline & 16 & 23 & 3.1 & 0 & $>22$ & Oct & 10 & 23 & 3.7 & 8 & 67 \\
\hline & 27 & 14 & 4.4 & 10 & $\sim 600$ & & 17 & 09 & 4.9 & 420 & 81 \\
\hline Nov & 1 & 14 & 3.2 & 0 & $>32$ & & 17 & 15 & 3.9 & 53 & 20 \\
\hline Dec & 6 & 08 & 4.7 & 788 & 21 & & 21 & 08 & 3.6 & 0 & $>130$ \\
\hline
\end{tabular}


TABLE 1-Continued

\begin{tabular}{|c|c|c|c|c|c|c|c|c|c|c|}
\hline Date & \multirow{3}{*}{$\begin{array}{c}\text { Hour } \\
13\end{array}$} & \multirow{3}{*}{$\frac{M L}{3.4}$} & \multirow{3}{*}{$\frac{\begin{array}{c}A R_{300} \\
\left(\mathrm{~mm}^{2}\right)\end{array}}{0}$} & \multirow{3}{*}{$\frac{\underset{(\text { bars })}{\mu E_{G} / M_{0}}}{>63}$} & \multicolumn{2}{|c|}{ Date } & \multirow{2}{*}{$\frac{\text { Hour }}{04}$} & \multirow{2}{*}{$\frac{M_{L}}{3.5}$} & \multirow{2}{*}{$\frac{\begin{array}{r}A R_{300} \\
\left(\mathrm{~mm}^{2}\right)\end{array}}{12}$} & \multirow{2}{*}{\begin{tabular}{r}
\multicolumn{1}{c}{$\begin{array}{r}\text { (bars) } \\
\text { (b/Mo }\end{array}$} \\
22
\end{tabular}} \\
\hline Dec 22 & & & & & Jul & 12 & & & & \\
\hline 1966 & & & & & & 24 & 07 & 3.7 & 68 & 8 \\
\hline Jan 7 & 19 & 4.0 & 41 & 37 & Aug & 11 & 00 & 4.1 & 40 & 53 \\
\hline Mar 19 & 14 & 4.0 & 42 & 36 & Oet & 14 & 00 & 3.6 & 8 & 48 \\
\hline Apr 17 & 07 & 4.0 & 0 & $>500$ & & 14 & 00 & 3.5 & 0 & $>90$ \\
\hline May 22 & 07 & 5.5 & 11,530 & 23 & Dec & 18 & 17 & 5.2 & 5,520 & 17 \\
\hline 23 & 11 & 5.6 & 14,120 & 27 & & 31 & 23 & 4.3 & 653 & 6 \\
\hline Jun 21 & 09 & 4.1 & 1,380 & 2 & 1968 & & & & & \\
\hline 28 & 01 & 3.5 & 23 & 12 & Apr & 9 & 02 & 3.7 & 13 & 41 \\
\hline 28 & 04 & 4.9 & 7,057 & 5 & & 9 & 08 & 4.0 & 258 & 6 \\
\hline 28 & 04 & 5.8 & 152,000 & 5 & & 9 & 08 & 3.6 & 0 & $>130$ \\
\hline 28 & 13 & 3.3 & 0 & $>45$ & & 9 & 08 & 3.4 & 12 & 16 \\
\hline 28 & 20 & 3.4 & 3 & 60 & & 9 & 09 & 3.8 & 3 & 250 \\
\hline 29 & 02 & 4.1 & 125 & 17 & & 9 & 09 & 4.0 & 29 & 53 \\
\hline 29 & 08 & 3.2 & 24 & 4 & & 9 & 11 & 4.0 & 58 & 26 \\
\hline 29 & 13 & 3.8 & 69 & 11 & & 9 & 11 & 3.9 & 28 & 38 \\
\hline 29 & 19 & 4.9 & 5,247 & 7 & & 9 & 12 & 3.6 & 20 & 19 \\
\hline 30 & 01 & 4.1 & 342 & 6 & & 9 & 18 & 4.7 & 92 & 180 \\
\hline Jul & 09 & 3.5 & 14 & 18 & & 10 & 00 & 3.7 & 13 & 41 \\
\hline 15 & 10 & 4.0 & 33 & 46 & & 10 & 13 & 3.9 & 15 & 70 \\
\hline Sep 2 & 11 & 3.7 & 8 & 67 & & 11 & 15 & 3.7 & 15 & 36 \\
\hline 2 & 17 & 3.4 & 0 & $>190$ & & 13 & 01 & 3.3 & $<9$ & $>15$ \\
\hline Oct 11 & 16 & 4.4 & 330 & 18 & & 23 & 16 & 4.1 & 90 & 25 \\
\hline 27 & 12 & 4.2 & 216 & 14 & May & 2 & 00 & 3.5 & 0 & $>90$ \\
\hline $\begin{array}{l}1967 \\
\text { Feb } 18\end{array}$ & 18 & 3.6 & 18 & 21 & & 6 & 10 & 3.5 & 0 & $>90$ \\
\hline Mar 1 & 06 & 3.7 & 15 & 36 & & 7 & 07 & 3.3 & 0 & $>45$ \\
\hline 2 & 14 & 4.4 & 133 & 46 & & 8 & 16 & 3.3 & 0 & $>45$ \\
\hline 13 & 21 & 3.6 & 0 & $>126$ & & 10 & 05 & 3.3 & 0 & $>45$ \\
\hline May 21 & 14 & 4.7 & 310 & 55 & & 13 & 18 & 3.3 & 0 & $>45$ \\
\hline
\end{tabular}

equal to $3 \cdot 10^{11} \mathrm{dyne} / \mathrm{cm}^{2}$. However, this assumption does not affect the results since $\mu$ is already inherent in the moment determination (Aki, 1966).

$$
M_{0}=\mu A D
$$

where $A$ equals the rupture area and $D$ equals the average displacement on $A$. $\mu$ therefore cancels out in ratio (1).

The data are given in Tables 1 and 2. The locations were not included for brevity. They can be obtained from the Pasadena local bulletins (Richter et al., 1967; Allen et al., 1968). For the years 1961 and 1962, the information is available at the Seismological Laboratory, California Institute of Technology. Table 1 contains the earthquakes for which $A R$ from Pasadena (PAS) was available only. For the earthquakes in Table 2 Pasadena (PAS), Berkeley (BRK), Ruth, Nevada $\left(39^{\circ} 15^{\prime} 00^{\prime \prime} \mathrm{N} / 115^{\circ} 00^{\prime} 00^{\prime \prime} \mathrm{W}\right)$ and Reno, Nevada $\left(39^{\circ} 32^{\prime} 24^{\prime \prime} \mathrm{N} / 119^{\circ} 48^{\prime} 47^{\prime \prime} \mathrm{W}\right)$, furnished $A R$ values. The data in Table 2 were previously used by Brune et al. (1963).

\section{DISCUSSION}

Parkfield versus Borrego Mountain. During the last four years, two medium-sized earthquakes occurred in southern California, the Parkfield 1966 and the Borrego Mountain 1968 events. They had magnitudes of 5.8 and 6.4, respectively. Both produced surface ruptures and large numbers of aftershocks. In both events, the U. S. 
TABLE 2

aR Values Recorded At Four Western Stations

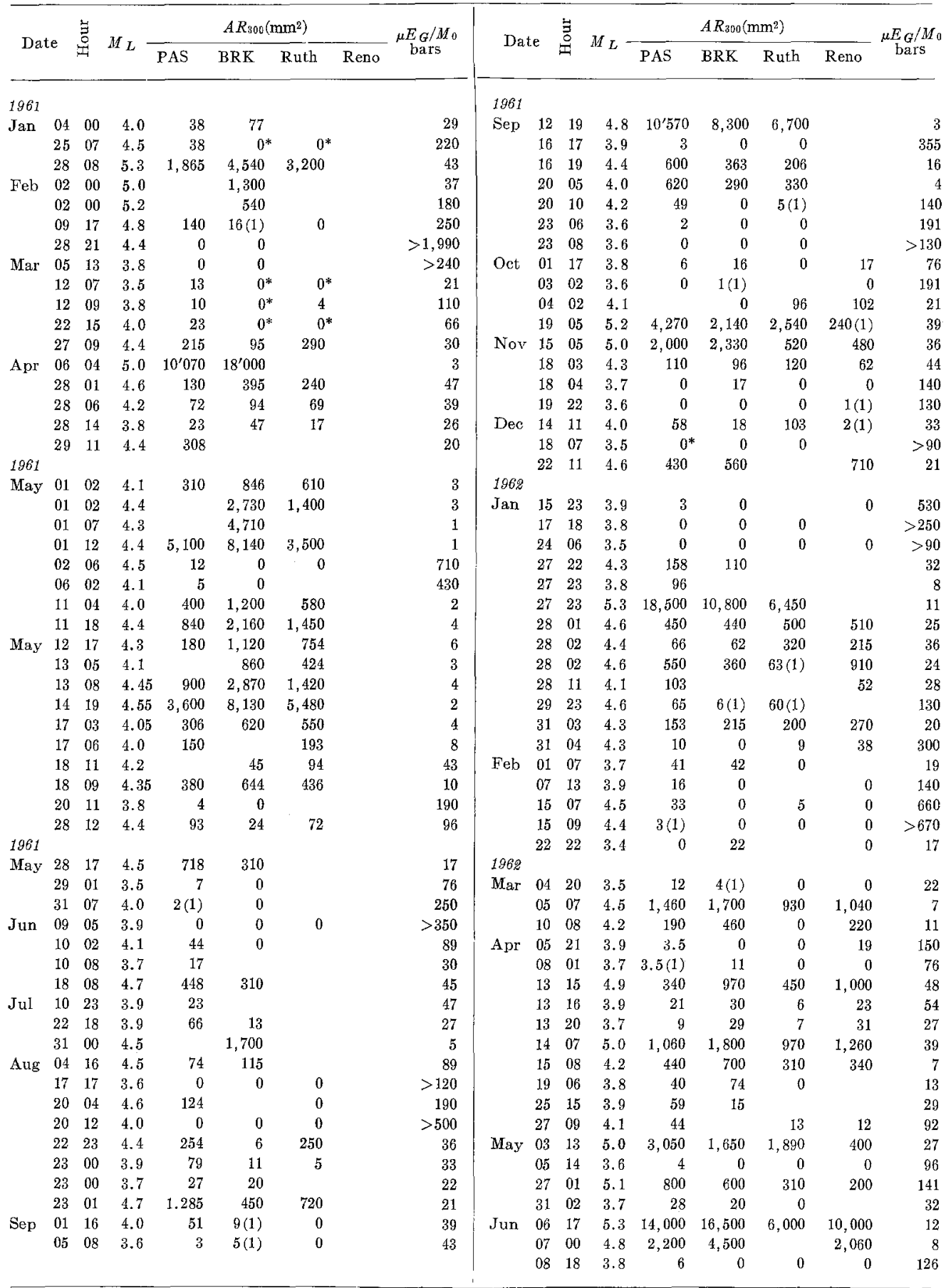

Geological Survey determined the hypocenters of many aftershocks with great accuracy (Eaton et al., 1970; Hamilton, in preparation). These two occurrences, therefore, present ideal opportunities to study the change of the parameter $c \bar{\sigma}$ with depth and to compare the level of $c \bar{\sigma}$ in the two regions. Seismograms for the two regions recorded 
at Pasadena are compared in Figure 3. It is evident that the Parkfield event produced relatively larger surface waves than the Borrego Mountain event. Table 3 contains a list of earthquakes in these two regions for which $A R$ was determined and depths with precisions of better than $2 \mathrm{~km}$ were available (Eaton et al., 1970; Hamilton, in preparation). The last column of Table 3 contains the ratio of high- to low-frequency radiation in terms of the apparent stress. These values are plotted as a function of depth in Figure 4.

The abscissa of Figure 4 is in bars. However, as was pointed out above, these values are only meant for comparison with each other, and do not represent the actual in-situ stress. Particularly, it should be remembered that for deeper earthquakes the plotted value of $c \bar{\sigma}$ is overestimated relative to shallow ones. Figure 4 demonstrates, however, two significant differences between the Parkfield and the Borrego Mountain aftershocks. (1) The high- to low-frequency ratio is larger for all depths at Borrego Mountain than it is at Parkfield. (2) The low-frequency content decreases with depth at Borrego Mountain but stays constant at Parkfield.

The relative increase of the high-frequency content with depth observed at Borrego

TABLE 3

Aftershocks with Accurate Depth Determinations

\begin{tabular}{|c|c|c|c|c|c|c|c|c|c|c|}
\hline Location & Date & & $\underset{(m)}{m e}$ & $M_{L}$ & $\begin{array}{c}\text { Depth } \\
\text { (USGS) } \\
(\mathrm{km})\end{array}$ & $\begin{array}{l}A R_{300} \\
\left(\mathrm{~mm}^{2}\right)\end{array}$ & $\begin{array}{c}\text { Moment } \\
M_{0}\left(10^{21}\right. \\
\text { dyne } / \mathrm{cm})\end{array}$ & $\begin{array}{c}\text { Energy } \\
E_{G} \\
\left(10^{16} \text { erg }\right)\end{array}$ & $\begin{array}{c}\text { Strain } \\
c \bar{\epsilon} \\
\left(10^{-5}\right)\end{array}$ & $\begin{array}{c}\text { Stress } \\
\overline{c \sigma} \\
\text { (bar) }\end{array}$ \\
\hline Borrego & 14. Apr. 68 & 12 & 55 & 4.3 & $10.8^{*}$ & 28. & 3.6 & 178. & 50 . & 150 \\
\hline Borrego & 15 Apr. 68 & 12 & 28 & 3.5 & $3.0^{*}$ & 6.6 & 0.8 & 11. & 14. & 42 \\
\hline Borrego & 16 Apr. 68 & 03 & 30 & 4.8 & $8.3^{*}$ & 354 . & 45 . & 1,000 & 23 . & 68. \\
\hline Borrego & 17 Apr. 68 & 02 & 43 & 3.7 & $7.9^{*}$ & $\leq 9$. & $\leq 1.1$ & 22 . & $\geq 20$. & $\geq 60$ \\
\hline Borrego & 06 May 68 & 17 & 31 & 4.0 & $6.7^{*}$ & 26 . & 3.2 & 63. & 20 . & 60. \\
\hline Borrego & 11 May 68 & 08 & 10 & 4.2 & $8.8^{*}$ & 37. & 4.7 & 126. & 27 . & 81. \\
\hline Borrego & 22 May 68 & 13 & 26 & 4.4 & $7.5^{*}$ & 52. & 6.6 & 250 . & 38. & 114. \\
\hline Parkfield & 02 July 66 & 12 & 08 & 3.6 & $8.0 \dagger$ & 47. & 7.3 & 16. & 2.2 & 6.6 \\
\hline Parkfield & 02 July 66 & 12 & 16 & 3.2 & $9.1 \dagger$ & 13 . & 2.5 & 4. & 1.6 & 4.8 \\
\hline Parkfield & 02 July 66 & 12 & 25 & 3.1 & $8.2 \dagger$ & 0 . & $<2$. & 2.8 & $>1.4$ & $>4.3$ \\
\hline Parkfield & 03 Aug. 66 & 12 & 39 & 3.7 & $5.1 \uparrow$ & 86. & 11. & 22 . & 2. & 6.0 \\
\hline Parkfield & 19 Aug. 66 & 22 & 51 & 3.4 & $0.1 \dagger$ & 26. & 3.2 & 8. & 2.5 & 5.0 \\
\hline
\end{tabular}

* Hamilton (in preparation).

† Eaton et al. (1970).

Mountain is in agreement with the observations of Tsujiura (1969). This observation indicates that the energy density of deeper sources is larger, which in turn means smaller dimensions of equal magnitude events. This behavior could be expected due to the larger hydrostatic pressure and, therefore, greater frictional resistance at depth. The lack of increased high-frequency radiation with depth at Parkfield suggests that the friction on the fault surface is reduced.

Parkfield is located on the southern end of the fault zone characterized by creep (Tocher, 1960; Brown and Wallace, 1968). Allen (1968) suggested that the occurrence of creep along the San Andreas can be correlated with the presence of serpentine, and Byerlee and Brace (1968) have shown that rocks containing serpentine respond to axial strain by stable sliding rather than by stick-slip as other rocks, granite for instance, do. At Parkfield the basement rock west of the fault is granite opposite Franciscan basement containing serpentinite on the east side of the fault (Dickinson, 1966). At Borrego Mountain the basement on both sides of the fault consists of granite (Dibblee, 1954). 
In view of the creep properties of serpentinite, it is tempting to propose that the presence of the Franciscan basement at Parkfield is responsible for the low apparent stresses observed. However, Raleigh and Paterson (1965) have shown in the laboratory that serpentine does not dehydrate below $300^{\circ} \mathrm{C}$, and that serpentinite below this temperature is comparable in strength to granite. Since the temperatures at depths between 5 and $10 \mathrm{~km}$ are expected to be below $300^{\circ} \mathrm{C}$ the dehydration mechanism seems to be ruled out in general as an explanation for the low apparent stress. However, in the Parkfield region, temperature could still be an important parameter. Heat-flow measurements near Hollister indicate that the temperatures are anomalously high in the Franciscan Block (Brune, 1969) to a degree that may be sufficient to produce weakening of the serpentinite.

Another difference between the two aftershock sequences was pointed out by Hamilton (in preparation) and Allen and Nordquist (in preparation): Many of the Borrego

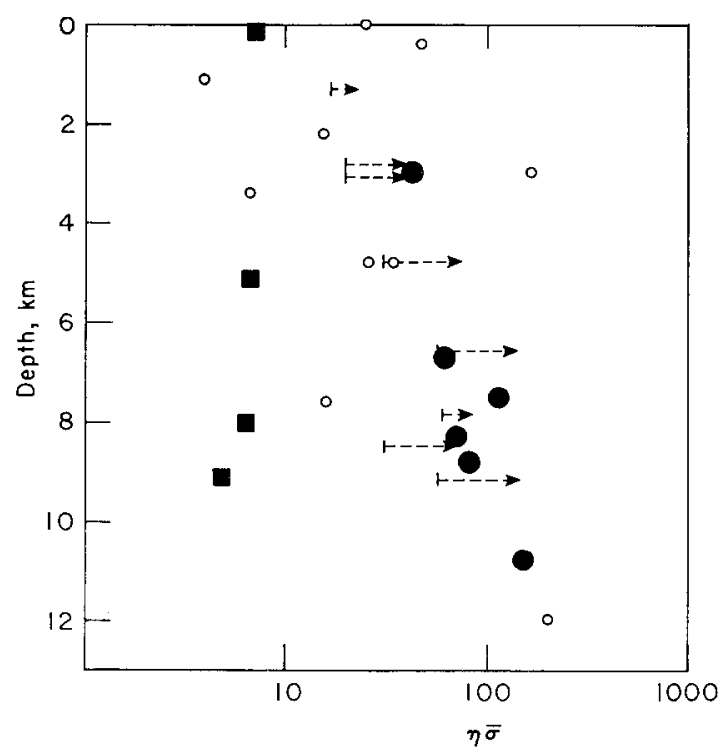

FIG. 4. The ratio of short- to long-period amplitude, expressed as apparent stress, at Borrego Mountain (circles and arrows) compared to Parkfield (squares). The abseissa is in bars. Large symbols indicate depths by Eaton et al. (1970) and Hamilton (in preparation); small symbols, depths by Pasadena bulletin. Arrows are minimum estimates for Borrego Mountain earthquake.

Mountain aftershocks did not occur on the main faulting surface as they did at Parkfield (Eaton et al., 1970). The locations of the aftershocks suggest that at Parkfield the fault surface is a well-developed zone of weakness whereas at Borrego it is less welldefined. This difference can explain the difference in the level of apparent stress but it does not explain the different behavior as a function of depth in the two regions.

More detailed studies of the variation of source parameters with depth are needed before the question of possible different faulting mechanisms can be resolved.

Regional variations of stress in southern California. The comparison of the high- to low-frequency ratio in southern California is more speculative because the depths of most earthquakes are not well-known. In Figure 5 the apparent stresses of southern California earthquakes for which an $A R$ value could be obtained between 1961 and 1967 are plotted. Large values indicate relatively weak low-frequency surface-wave radiation which could be due to relatively greater depth of the source, to greater efficiency of the source mechanism, or to relatively greater stresses in the source region, 


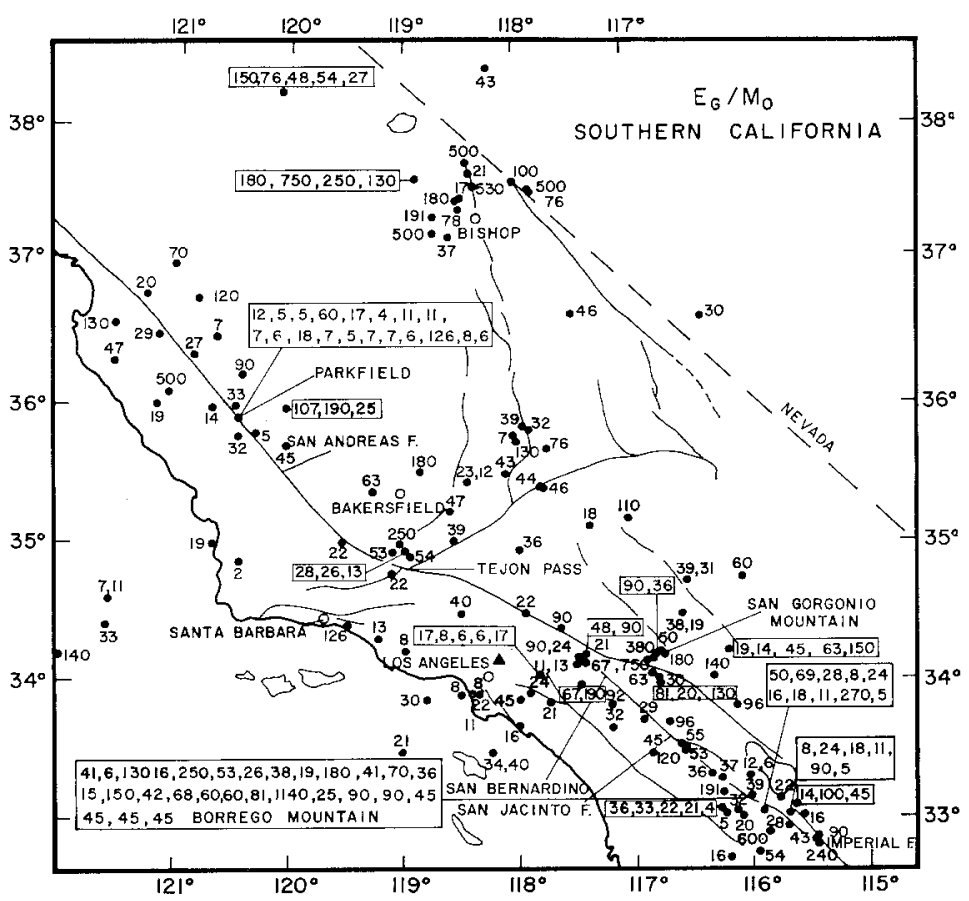

FIG. 5. Apparent stresses in southern California given in bars. The dots next to the numbers indicate the epicenters. The apparent stresses of aftershock sequences are given in boxes with a straight line indicating the epicentral region. Pasadena station is marked by a triangle.

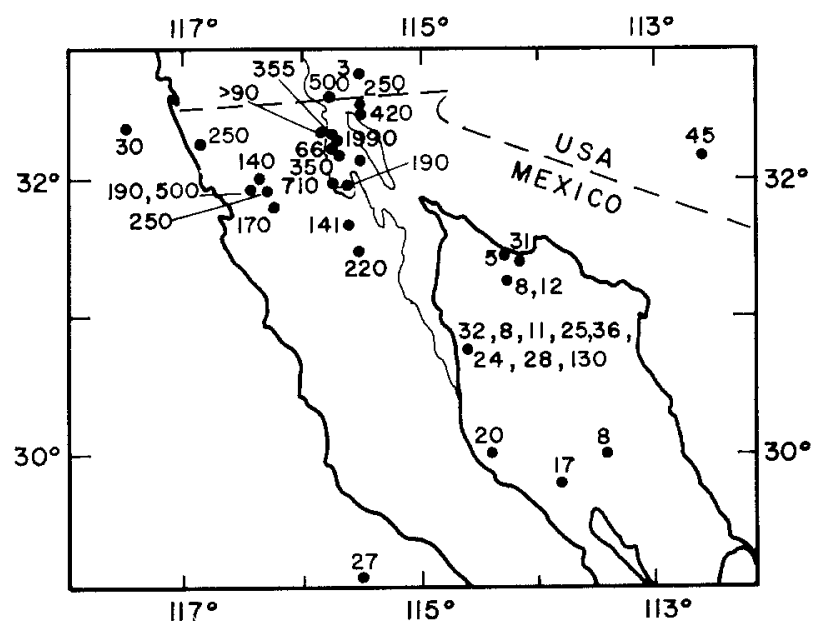

Frg. 6. Apparent stresses in Baja California and the Gulf of California. The fine line in northern Baja California separates the geological provinces of the southern California batholith to the west and the Laguna Salada to the east of it. Symbols are the same as in Figure 5.

which in turn implies greater strength of these source regions. Figures 6 and 7 are maps for the region south of the Mexican border and the Mendocino fracture zone.

The question of how the hypocentral depths affect the data presented in Figures 5, 6 , and 7 could not be resolved satisfactorily because the depths are not well enough known. During the years 1963 to 1967 , the Pasadena bulletins did list depths; before that time they did not. In order to see whether another factor than depth influences 
the apparent stresses, the data were searched for shallow earthquakes $(h<6 \mathrm{~km})$ with relatively high apparent stresses $(c \bar{\sigma}>100$ bars $)$, and for deeper ones $(h>11 \mathrm{~km})$ with relatively low apparent stresses ( $c \bar{\sigma}<25$ bars). Only shocks within the California Institute of Technology network were considered. For each of these categories, eight earthquakes with quality B locations by Pasadena could be found. However, C. R. Allen pointed out to us that, in the future, the Pasadena bulletins will not give any depth values unless one station is located as close as $20 \mathrm{~km}$ from the epicenter. A comparison of six hypocenter locations by Pasadena with the more accurate ones by Hamilton (in preparation) indicates that Pasadena quality B locations using one station as close as $20 \mathrm{~km}$ give meaningful depths and differ by $\pm 2 \mathrm{~km}$ from the locations based on the field array (Hamilton, in preparation).

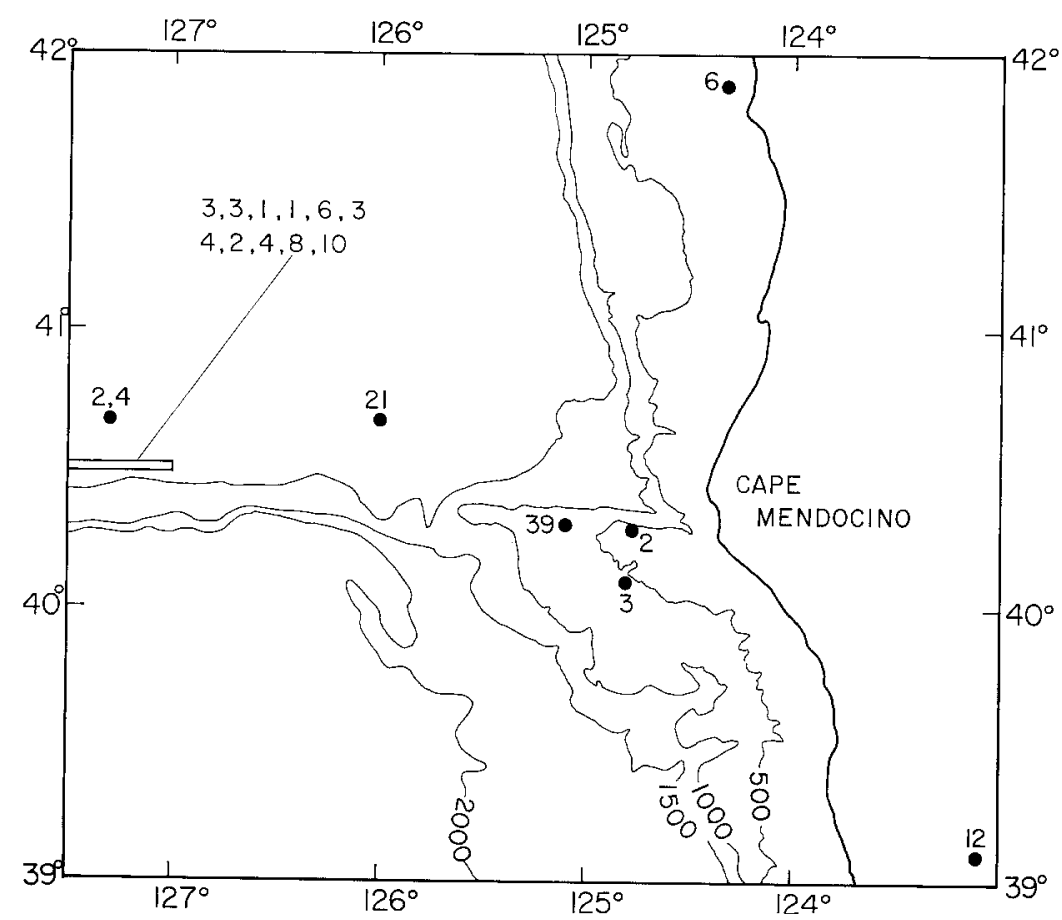

FIG. 7. Apparent stresses on the Mendocino fracture zone. Symbols are the same as in Figure 5

Only four of 16 earthquakes in the two categories fulfilled the condition that a station be as close as $20 \mathrm{~km}$ to the epicenter. These earthquakes and the closest stations are given in Table 4 . Only one of them is relatively shallow with a high stress. These data together with the data presented in Table 3 and Figure 4 suggest that there is a factor other than depth influencing the apparent stress. It is proposed that this additional factor is the stress in the source region. It must, however, be conceded that in any region where the hypocentral depths are not known, anomalously high apparent stresses could be solely due to greater depth of the earthquakes there.

Figures 5, 6 and 7 show that along the major fault zones the $c \bar{\sigma}$ values are generally low. The seismically most active portions of the San Andreas and Oceanic faults have the lowest values. The few earthquakes which occurred in the seismically quiet portions of the San Andreas (see Allen, 1968) tend to have somewhat higher apparent stress values. Long segments of the San Andreas had no earthquakes during the time interval studied and nothing can be said about the apparent stresses there. The earthquakes 
which occurred near the two bends in the San Andreas fault near Tejon Pass and San Gorgonio Mountain, show intermediate apparent stresses. It is possible that these two regions act as locking points (Benioff, 1949) and, therefore, concentrate higher stresses.

Other intermediate apparent stresses are indicated from San Bernardino southward along the San Jacinto fault. These observations agree with Smith and Van de Lindt (1969) who concluded that large stresses should be accumulated just north of San Bernardino. Brune (1969) also concluded that the high stresses should be accumulated near San Gorgonio Pass and near the northern end of the San Jacinto fault.

The regions of high apparent stress values are located off the main transform fault system of the San Andreas. Conspicuously low surface-wave radiation is observed north of Bishop and in northern Baja California as previously noted by Brune et al. (1963). It may be that the earthquakes in these two regions occur at greater depth than in the rest of California. An alternative explanation of the high apparent stress

TABLE 4

Values from Stations Located as Close as 20 KM from Epicenters of EARTHQUAKES

\begin{tabular}{|c|c|c|c|c|c|c|c|}
\hline$(\mathrm{deg})$ & $\mathrm{em}_{\mathrm{min}}^{\mathrm{N}}$ & $\begin{array}{c}\text { Longi } \\
\text { (deg) }\end{array}$ & $\underset{(\min )}{W}$ & Date/Station & $M_{L}$ & $\underset{(\mathrm{km})}{\text { Depth }}$ & $\overline{c \sigma}$ \\
\hline \multicolumn{8}{|c|}{ Deep Low-Stress Earthquakes } \\
\hline 32 & 58.9 & 115 & 33.9 & 23 May 1963 & \multirow[t]{2}{*}{4.6} & \multirow[t]{2}{*}{$>14$} & \multirow[t]{2}{*}{16} \\
\hline 32 & 47.9 & 115 & 32.5 & El Centro & & & \\
\hline 33 & 55.7 & 118 & 20.9 & 8 May 1963 & \multirow[t]{2}{*}{2.7} & \multirow[t]{2}{*}{17} & \multirow[t]{2}{*}{8} \\
\hline 34 & 08.9 & 118 & 10.3 & Pasadena & & & \\
\hline 34 & 55.9 & 118 & 58.5 & 1 March 1963 & \multirow[t]{2}{*}{5.0} & \multirow[t]{2}{*}{14} & \multirow[t]{2}{*}{28} \\
\hline 34 & 52.4 & 118 & 53.6 & Fort Tejon & & & \\
\hline \multicolumn{8}{|c|}{ Shallow High-Stress Earthquakes } \\
\hline 35 & 31,0 & 118 & 51.2 & 31 May 1964 & 3.7 & 6 & $>180$ \\
\hline 35 & 42.0 & 118 & 50.6 & Woody & & & \\
\hline
\end{tabular}

values is that the faults in these regions are less well developed than the San Andreas fault system and greater stresses are accumulating before rupture occurs.

The data presented in Figures 5, 6, and 7 include a number of aftershock sequences. In these figures the apparent stresses of aftershock sequences are given in boxes. The values follow in the order of occurrence. In these sequences there is no decrease of apparent stress with time observed. The reason for this is that the fractional stress drop of the small earthquakes studied here $\left(M_{L}<5\right)$ is less than 10 per cent, more typically in the order of 1 per cent (King and Knopoff, 1968; Wyss, 1970) and the dimensions are small. Even the main shocks in these sequences, therefore, do not significantly reduce the average stress in the source region. Occasionally, some high apparent stresses can be observed in an aftershock sequence. These could be due to deeper events or to earthquakes originating in local stress concentrations produced by the main shock around the ends of the faulted area.

Besides the depth, there is another unknown factor in the results discussed above, namely, the efficiency of conversion of potential energy to seismic waves. This parameter could also vary from region to region. In view of these uncertainties the results presented here cannot be taken as proof of stress differences between source regions. It 
is hoped that the present study may stimulate further work with the aim of determining more precisely the reasons for the observed large differences in seismic radiation.

The discrimination problem. One of the most powerful tools in the discrimination between underground explosions and earthquakes is the $m_{b}-M_{s}$ method (e.g., SIPRI, 1968; Lacoss, 1969; Liebermann and Pomeroy, 1969; Molnar et al., 1969), a variation of which is the $A R$ method (Brune et al., 1963). The comparison of $A R$ to the short period amplitude was considered by Evernden (1969) to be an even better discriminator than the $M_{s}-m_{b}$ method. It is clear that earthquakes with relatively large $A R$ values, i.e., low apparent stresses, are easily distinguished from explosions. These are the typical Mendocino, San Andreas, and Gulf of California earthquakes. These earthquakes have relatively large fault dimensions (Wyss and Brune, 1968; Wyss et al., 1970) and they differ sufficiently in size from explosions in order to be discriminated on this basis alone.

High stress earthquakes like those on the California-Nevada border, in the Laguna Salada region, and the San Gorgonio Pass region (Hanks and Brune, 1970) have considerably smaller source dimensions. Other earthquakes with small source dimensions were discussed by McEvilly (1966) and Ryall et al. (1968). These high-stress earthquakes are the most likely ones to be confused with explosions. It should be determined whether and how these earthquakes can successfully be discriminated from explosions. If they and other earthquakes from high-stress regions can be discriminated at a given magnitude level, then the discrimination problem is solved for that magnitude level and above.

\section{ConClusions}

It has been shown that large variations in the amplitude ratio of high- to low-frequency seismic waves exist between local earthquakes in California. It has also been shown that these differences are not only a function of depth. The explanation for the large variation of surface-wave excitation (apparent stress) is not known for certain, however, it is proposed that the main factor causing these differences may be the stress in the source region. A more detailed comparison showed that in the Borrego Mountain region the apparent stress is higher at all depths than in the Parkfield region. Furthermore, in the Borrego Mountain region the high- to low-frequency amplitude ratio increases with depth, whereas at Parkfield it is independent of depth.

A tentative apparent stress map of southern California is constructed. This map suggests that the San Bernardino-San Gorgonio Mountain region is under higher stresses than the seismically more active regions of the San Andreas fault system. High apparent stresses are observed north of Bishop and in the northern Baja California region. These earthquakes are expected to produce earthquakes of the type that are the most difficult to distinguish from underground explosions.

\section{ACKNOWLEDGMENTS}

Most of this research was carried out while the authors were associated with the California Institute of Technology. The extensive and helpful critical comments by Dr. C. R. Allen which lead to substantial improvement of the manuscript are gratefully acknowledged. The authors wish to thank Dr. P. Molnar, Dr. B. Isacks, and Dr. L. Sykes who read the manuscript and made many helpful comments. This research was supported by National Science Foundation grant NSF-GA-12868 and NSF-GA-22709.

\section{RefeRENCES}

Aki, K. (1966). Generation and propagation of G waves from the Niigata earthquake of June 16, 1964, Part 2, Estimation of earthquake moment, released energy, and stress-strain drop from the G wave spectrum, Bull. Earthquake Res. Inst., Tokyo Univ., 44, 73-88. 
Allen, C. R. (1968). The tectonic environments of seismically active and inactive areas along the San Andreas fault system, Proceedings of the Conference on Geological Problems of the San Andreas Fault System, Stanford University, pp. 14-16.

Allen, C. R., J. N. Brune, J. M. Nordquist, C. F. Richter, V. Taylor (1968). Local Bulletin of Earthquakes in the Southern California Region, January 1967 to 31 Decermber 1967, Seismological Laboratory, California Institute of Technology.

Allen, C. R., J. M. Nordquist, Borrego Mountain earthquake: Foreshock, mainshock, and larger aftershocks, U. S. Geol. Surv., Profess. Paper (in preparation).

Benioff, H. (1949). Seismic evidence for the fault origin of oceanic deeps, Bull. Geol. Soc. Am. 60, $1837-1856$.

Brown, R. D., Jr. and R. E. Wallace (1968). Current and historic fault movement along the San Andreas fault between Paicines and Camp Dix, California, Proceedings of the Conference on Geologic Problems of the San Andreas Fault System, Stanford Univ. Publ., Geol. Sci. 16.

Brune, J. N., A. Espinosa, and J. Oliver (1963). Relative excitation of surface waves by earthquakes and underground explosions in the California-Nevada region, J. Geophys. Res., 68, $3501-3513$.

Brune, J. N. (1969). Seismicity, rate of slip, stress and heat flow along the San Andreas fault in California, E.O.S. Trans. Amer. Geophys. Union, Abstract 50, 384.

Byerlee, J. D. and W. F. Brace (1968). Stick slip, stable sliding, and earthquakes-effect of rock type, pressure, strain rate, and stiffness, J. Geophys. Res. 73, 6031.

Dibblee, T. W., Jr. (1954.) Geology of the Imperial Valley region, California, Calif. Dep. Nat. Resources, Div. Mines Bull. 170, 23-34.

Dickinson, W. R. (1966). Structural relationships of San Andreas fault system, Cholame Valley and Castle Mountain Range, California, Geol. Soc. Am. Bull. 77, 707-726.

Eaton, J. P., M. E. O'Neill, and J. N. Murdock (1970). Aftershocks of the 1966 Parkfield-Cholame, California, earthquake: A detailed study, Bull. Seism. Soc. Am. 60, 1151-1197.

Evernden, J. F. (1969). Identification of earthquakes and explosions by use of teleseismic data, J. Geophys. Res., 74, 3828 .

Gutenberg, B. and C. F. Richter (1956). Magnitude and energy of earthquakes, Ann. Geof. (Rome) 9, 1-15.

Hamilton, R. (in preparation). Aftershocks of the Borrego Mountain, California, earthquake from April 12 to June 12, 1968, U. S. Geol. Surv., Profess. Paper.

Hanks, T. and J. Brune (1970). San Gorgonio Pass locations and stress (in preparation).

King, C. and L. Knopoff (1968). Stress drop in earthquakes, Bull. Seism. Soc. Am. 58, 249-258.

Lacoss, R. T. (1969). A large population LASA discrimination experiment, Technical Note 196924, Lincoln Laboratory, Massachusetts Institute of Technology.

Liebermann, R. C. and P. W. Pomeroy (1969). Relative excitation of surf ace waves by earthquakes and underground nuclear explosions, $J$. Geophys. Res. 74, 1575-1590.

Molnar, P., J. Savino, L. R. Sykes, R. C. Liebermann, G. Hade, and P. W. Pomeroy (1969). Small earthquakes and explosions in western North America recorded by new high gain, long period seismographs, Nature, 224, 1268-1273.

McEvilly, T. V. (1966). The earthquake sequence of November 1964 near Corralitos, California, Bull. Seism. Soc. Am. 56, 755-773.

Raleigh, C. B. and M. S. Paterson (1965). Experimental deformation of serpentinite and its tectonic implications, J. Geophys. Res. 70, 3965-3985.

Richter, C. F., J. M. Nordquist, V. Taylor, and C. R. Allen (1967). Local Bulletin of Earthquakes in the Southern California Region, January 1, 1963 to December 31, 1966, Seismological Laboratory, California Institute of Technology.

Ryall, A. J., J. D. Van Wormer, and A. E. Jones (1968). Triggering of microearthquakes by earth tides, and other features of the Truckee, California earthquake sequence of September 1966, Bull. Seism. Soc. Am. 58, 215-248.

SIPRI (1968). Seismic methods for monitoring underground explosions, Report by a seismic study group, International Institute for Peace and Conflict Research (SIPRI), Stockholm, $130 \mathrm{pp}$.

Smith, S. W. and W. Van de Lindt (1969). Strain adjustment associated with earthquakes in Southern California, Bull. Seism. Soc. Am. 59, 1569.

Tocher, D. (1960). Creep on the San Andreas fault-Creep rate and related measurements at Vineyard, California, Bull. Seism. Soc. Am. 50, 396-404.

Tsai, Y. (1969). Determination of focal depths of earthquakes in the mid-oceanic ridges from amplitude spectra of surface waves, Ph.D. Thesis, Massachusetts Institute of Technology. 
REGIONAL, VARLATIONS OF SOURCE PROPERTIES IN SOUTHERN CALIFORNIA 1167

Tsujiura, M. (1969). Regional variation of P-wave spectrum (1), Bull. of the Earthquake Res. Inst., Tokyo University 47, 613-633.

Wyss, M. and J. N. Brune (1968). Seismic moment, stress and source dimensions for earthquakes in the California-Nevada region, $J$. Geophys. Res., 73, 4681-4694.

Wyss, M., J. N. Brune, T. C. Hanks, and B. E. Tucker (1970). Source dimensions of nuclear explosions and small shallow earthquakes, ARPA Meeting, Woods Hole.

Wyss, M. (1970). Observation and interpretation of tectonic strain release mechanisms, Ph.D. Thesis, California Institute Technology, 1970.

Lamont-Doherty Geological Observatory Columbia University

Palisades, New York, 10964 (M.W.)

Division of Geological Sctences

California Institute of Technology

Pasadena, California

Contribution No. 1949

Manuscript received November 23, 1970.
Institute of Geophysics and

Planetary Physics

and Scripps Institute of Oceanography

UNIVERSITY OF CALIFORNIA

SaN Drego, Californta (J.N.B.) 